\title{
Fabricação Digital Aplicada à Habitação de Caráter Emergencial: Um estudo sobre a adaptação de WikiHouses ao contexto ambiental brasileiro
}

\author{
Digital Fabrication Applied to Temporary Houses for Post-disaster and Social Emergency: A \\ study on the adaptation of WikiHouses to the Brazilian tropics
}

\author{
Bruna Branco \\ Universidade Católica de Pernambuco, Brasil \\ brunasbranco@gmail.com \\ Robson Canuto \\ Universidade Católica de Pernambuco, Brasil \\ robsoncanuto.arq@gmail.com
}

\author{
Aristóteles Cantalice \\ Universidade Católica de Pernambuco, Brasil \\ cantalice2@gmail.com
}

\begin{abstract}
Digital fabrication has transformed the way buildings are constructed by applying methods such as friction-fit connection. This technique has been propagated by WikiHouse which aims to develop open building technologies to different environmental contexts. However, the indiscriminate use of the model may result in inefficiency of housing performance. This work, therefore, investigates solutions for adapting WikiHouses to the tropics, according to principles proposed by Armando de Holanda in 'A Guide to Build in Northeast Brazil'. Nevertheless, difficulties related to certain adaptations were observed such as connections compatibility and design of large open spaces, especially because these systems depend on a maximum size of parts.
\end{abstract}

Keywords: Digital fabrication; Temporary houses; Post-traumatic urbanism; Friction-fit Connection, WikHouse.

\section{Introdução}

A fabricação digital vem transformando o modo como construímos edifícios e apresenta grande potencial para a produção de unidades habitacionais pré-fabricadas, seja com o propósito de atender demandas de personalização em massa, interesse social ou situações emergenciais pósdesastre. Nos últimos anos, diversas investigações vêm sendo desenvolvidas no sentido de aplicar técnicas de fabricação digital à produção de habitação, por meio de métodos como o contour crafting e o friction-fit connection (Sass \& Botha, 2006; Khoshnevis, 2004; Passaro \& Rodhe, 2014; Wikihouse, 2016).

O método friction-fit connection vem sendo bastante empregado em edifícios residenciais. Trata-se de uma técnica onde as partes construtivas são subdivididas em partes para serem montadas a posteriori por meio de encaixes. Neste, as peças são fabricadas através de corte em fresadoras, técnica que vem sendo propagada pela WikiHouse, uma plataforma aberta de construção cujo objetivo é desenvolver unidades habitacionais e compartilhá-las na web, disponibilizando projetos para download e impressão em máquinas CNC.

Apesar dos criadores do WikiHouse terem o intuito de promover soluções rápidas de construção de habitação, bem como defenderem a adaptação desse sistema a diferentes contextos ambientais, econômicos e socioculturais, sua adequação não é tão simples. De modo que, seu uso indiscriminado, sem considerar essas adaptações ao contexto, pode resultar em prejuízos para o desempenho da habitação.

O trabalho busca investigar soluções de adaptação de plataformas abertas de construção, particularmente das WikiHouses (Wikihouse, 2016), ao contexto ambiental do Nordeste brasileiro, tendo como base os princípios contidos no livro Roteiro para Construir no Nordeste de Armando de Holanda (1976). Objetiva-se desenvolver protótipos de habitação para situações que vêm sendo descritas na literatura como post-traumatic urbanism (urbanismo póstraumático) (Lahoud, 2010, p.14-23), causadas por desastres naturais ou conflitos, fazendo com que centenas de indivíduos percam suas habitações e seus familiares, mas onde se verifica a resiliência - capacidade de um sistema urbano de se recuperar depois de algum choque.

\section{Da Pré-fabricação à Fabricação Digital de Habitação}

A pré-fabricação de unidades habitacionais por meio da subdivisão da construção em partes para montagem in loco não é uma invenção contemporânea. Entre os séculos XVII e XIX, como forma de facilitar a colonização do território australiano, a Inglaterra já transportava abrigos simples estruturados por meio de quadros de madeira para montagem no local (Smith, 2011, p.05). Ao final do século XIX, também na Inglaterra, unidades habitacionais unifamiliares fabricadas por meio de sistemas de pré-corte de madeira já eram comercializadas pioneiramente pela companhia Aladdin 
Homes. No mesmo período, nos EUA, o método balloon frame também era popular. Compreendia-se, já naqueles anos, que esses processos reduziam resíduos, aumentavam a velocidade de produção, melhoravam a precisão e diminuíam o tempo de construção (Smith, 2011, p.09).

Ao longo do século $X X$, o desenvolvimento da pré-fabricação acompanhou transformações trazidas pela industrialização, aproveitando-se de processos e tecnologias de produção advindas do fordismo, orientando-se por princípios de padronização, produção em massa e permutabilidade, capazes de fornecer produtos mais precisos e diminuir o tempo de produção. Esses desenvolvimentos tiveram grande impacto na produção de arquitetura moderna, especialmente na produção de arquitetos como Walter Gropius, Jean Prouvé, Mies Van der Rohe e Frank Lloyd Wright. Sistemas de habitações pré-fabricadas classificados como kit-of-houses; painéis, volumétricos e semi-volumétricos (Votava, 2006) ocuparam especial lugar no repertório da arquitetura moderna e, em particular, no trabalho desses arquitetos. (Figura 1).

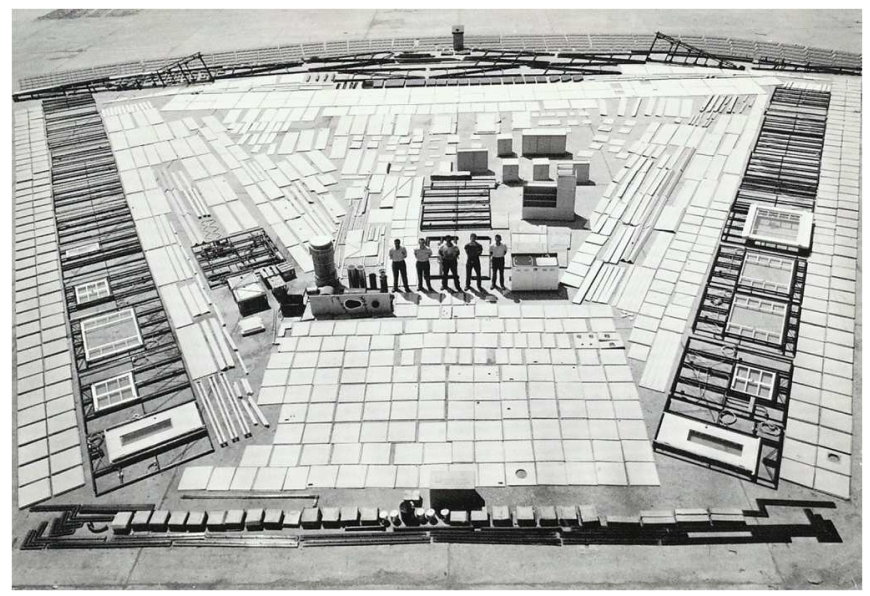

Figura 1: Unidade de habitação pré-fabricada, sistema kit-ofhouses. (Lustron Homes by Lustron Corporation, Columbus, Ohio, USA Carl Stranlund)

Arnt Cobbers \& Oliver Jahn (2014, p.99)

A partir da segunda metade do século $X X$, a disseminação das tecnologias CAD, CAM e CNC levaram à automação de processos industriais. Essas tecnologias, antes restritas às indústrias automobilística, naval e aeroespacial, migraram para a indústria da construção com significativo impacto nos sistemas de pré-fabricação. Esse conjunto de ferramentas, técnicas e processos automatizados de construção tem sido denominado na literatura como 'fabricação digital'.

A Fabricação Digital vem sendo cada vez mais aplicada à produção de edifícios inteiros ou à produção de partes deles, por meio de métodos como o contour crafting e o friction-fit connection. Enquanto o primeiro emprega métodos aditivos, 0 segundo utiliza modos subtrativos de fabricação. O contour crafting, de modo geral, utiliza guindastes robôs que possuem movimentação em três eixos para facilitar a deposição de materiais como concreto, cerâmica e metal, com a vantagem da precisão de construção, a exemplo da $3 D$ printed house. $O$ método friction-fit connection, por outro lado, é uma técnica de fabricação de componentes de um edifício bastante utilizada em sistemas construtivos pré-fabricados, em que a construção é completamente subdividida em partes para serem montadas, posteriormente. Em geral, as peças são produzidas por fresadoras.

A fabricação digital tem grande potencial para aplicação na produção de sistemas pré-fabricados de habitação, aspecto atestado por diversas investigações desenvolvidas ao longo dos últimos anos, com diferentes propósitos tais como: (1) atender às demandas de personalização habitacional; (2) equacionar questões relativas à autoconstrução e ao acesso à moradia (Passaro \& Rodhe, 2014); e (3) apoiar situações de emergência decorrentes de desastres naturais ou de conflitos civis (Saas \& Botha, 2006; Khoshnevis, 2004).

Greg Lynn investigou, entre 1997 e 2001, estratégias de produção de unidades habitacionais por meio de processos automatizados, esse projeto, chamado Embryological House, visava à personalização em massa. Lynn desenvolveu uma abordagem digital para o projeto inspirada pela biologia evolutiva, estabelecendo parâmetros para a geometria primitiva da casa e limites prescritivos. Por meio de combinações, produziu variações de casas preservando topologicamente a estrutura original. De fato, tratava-se de um sistema de geração de forma e espaço, de modo que uma mudança em qualquer componente alterava todos os outros componentes dentro do sistema, facilitando a personalização.

Recentemente, Passaro \& Rohde (2014) construíram a Casa Revista, um modelo de habitação de interesse social que empregava sistemas de construção fabricada digitalmente com o propósito de equacionar questões como o acesso à moradia no Brasil e a autoconstrução. A habitação foi pensada para o clima tropical, partindo do arquétipo da casa brasileira, com coberta de duas águas e aberturas zenitais para circulação de ar, melhorando a qualidade térmica e a iluminação natural. O projeto possibilitava a personalização, não apenas pelo acabamento, mas também pela facilidade de expansão, redução e combinação de arranjos (Passaro \& Rohde, 2014, p.06). Além disso, foi desenvolvida uma estratégia de compartilhamento do projeto, por meio de uma revista, para que pudesse ser vendida em qualquer banca de jornal, em um formato mais acessível ao grande público.

Em 2006 Sass \& Botha desenvolveram a Instant House, acreditando que no mundo contemporâneo deveria se especular, em algum momento, sobre a necessidade de substituição de habitações em comunidades destruídas por desastres naturais. Em 2008, Larry Sass empregou essa tecnologia da Instant House no desenvolvimento de protótipos de novas casas para New Orleans que, em 2005, havia sido arrasada após a passagem do furacão Katrina. O projeto, resultante de uma pesquisa desenvolvida no Massachusetts Institute of Technology (MIT), recebeu nome de "YourHouse" (Sass, 2014).

Embora estes exemplos sejam derivados de investigações projetuais oriundas da prática profissional ou da pesquisa acadêmica, demonstram que a aplicação da fabricação digital à produção de habitação é uma realidade, porém ainda pouco explorada pela construção civil, possivelmente, pela limitação das técnicas no que se refere à construção de grandes 
estruturas. Porém, seu impacto pode ser melhor mensurado quando se observa a emergência e disseminação global das WikiHouses.

\section{Fabricação Digital e Sistemas Open Source de Construção - os Limites das WikiHouses}

O grupo WikiHouse, desenvolvido pelo escritório Architecture 00 em parceria com Momentum Estrutura Engineers, possui endereço fixo em Londres, Inglaterra, mas já conquistou diversos colaboradores nos Estados Unidos, França, Espanha, e Nova Zelândia. O grupo desenvolve sistemas open source de construção para habitação, englobando três aspectos: desenvolvimento de plugin para software; construção de protótipos em escala real; e desenvolvimento de plataforma virtual aberta para a troca de dados e informação.

O WikiHouse apresenta suas tecnologias como sendo " o futuro da moradia" - soluções simples, sustentáveis e acessíveis a qualquer indivíduo. Permite-se que "cada um possa projetar a moradia como um código, instantaneamente personalizada para o local e o usuário, enquanto mantém controle de custo". (WikiHouse, 2016). Além disso, qualquer pessoa pode propor um projeto piloto (BETA) - um modelo de moradia WikiHouse que possa ser utilizada por outros usuários. Atualmente, são disponibilizadas 5 bibliotecas de arquivos, 35 arquivos individuais, além de o projeto ter 104 envolvidos, 210 repositórios e 5 projetos em desenvolvimento (WikiHouse, 2016).

Os sistemas de construção propagados pelo WikiHouse são baseados no conceito de friction-fit connection, como visto, método que se utiliza de fresadoras para impressão de componentes construtivos. A principal característica desse sistema é o encaixe, que permite a montagem e desmontagem do artefato arquitetônico sem necessidade de pregos, parafusos ou colas, mas apenas de pequeno grupo de pessoas para execução. Trata-se de sistema similar a um quebra-cabeça, cujas partes são desenhadas com encaixes para facilitar a montagem, garantindo rapidez de execução e flexibilidade, uma vez que peças podem ser desencaixadas, alteradas, ampliadas ou reduzidas. Em geral, são montados quadros da estrutura da habitação e, em seguida, peças são erguidas e encaixadas. Usualmente, os materiais empregados são madeira, painéis OSB ou MDF, aspecto pelo qual as casas são elevadas do solo e construídas sobre base de concreto, pedra ou outro material sólido.

De acordo com Passaro \& Rohde (2014, p.5), "o sistema proposto pela WikiHouse funciona com pórticos formados por peças de chapa de madeira compensada cortadas em fresadora CNC. As peças do pórtico são unidas por uma junção em "S", e o pórtico duplicado com o sentido do "S" invertido para garantir rigidez à junção. Os travamentos entre pórticos são feitos com peças transversais que se cruzam por orifícios no pórtico e são fixadas com cunhas. Esse sistema trava a estrutura nas três direções sem fazer uso de parafusos, apenas com encaixes de peças de madeira compensada. Tem-se o esqueleto da estrutura que é contraventado com a fixação de chapas de compensado de fechamento que se encaixam em abas da estrutura. "

Um exemplo desta tecnologia é a WikiHouse 4.0, produzida para o London Design Festival, em 2014, em parceria com a Arup, Architecture 00 e The Building Centre. Consiste em uma casa de dois pavimentos, com $68 \mathrm{~m}^{2}$, destinada a abrigar quatro pessoas. Após a montagem da estrutura, a vedação é feita pelas peças maiores, formando as paredes externas. $O$ usuário pode optar pela aplicação de revestimentos externos para melhor proteção do material. A colocação de janelas e portas também é feita nessa etapa, podendo os formatos e tamanhos serem escolhidos pelo usuário, aumentando a personalização.

De fato, o sistema WikiHouse proporciona soluções construtivas de rápida execução. A facilidade de montagem e desmontagem que tal sistema oferece, sem necessidade de mão de obra especializada, apresenta-se como solução ótima para atender demandas diversas como, por exemplo, a reconstrução de áreas afetadas por desastres naturais que exigem abrigos temporários ou moradias permanentes.

Todavia, os criadores do WikiHouse defendem que os projetos piloto possuam fácil adaptação a diferentes climas, culturas e economias, mas a adaptação desses sistemas a diferentes realidades ambientais não é tão simples como vêm sendo divulgada. A adaptação de WikiHouses ao contexto ambiental brasileiro - em particular, aos trópicos no Nordeste do Brasil, por exemplo, exige soluções técnicas sofisticadas que acabam por inviabilizar ou encarecer o custo da moradia. Para demonstrar a assertiva, investiga-se soluções de adaptação, visando ao desenvolvimento de um protótipo de habitação para situações pós-desastres no nordeste brasileiro.

\section{Adaptando WikiHouses ao Contexto Ambiental Brasileiro}

Como forma de investigar alternativas de adaptação de WikiHouses aos trópicos ensolarados, tomou-se como projeto piloto o arquivo BETA da WikiHouse 3.0 - um modelo pavilhonar hipotético de $80,0 \mathrm{~m}^{2}$. Trata-se de um modelo de vão livre adaptável a qualquer programa, sem divisões internas, com flexibilidade necessária para permitir os ensaios. Evidentemente, a área da habitação pode ser reduzida ou ampliada, conforme a necessidade de cada família ou uso.

A investigação associou a construção de modelos digitais e físicos. (Figura 6). Os modelos físicos foram fabricados digitalmente produzidos em duas escalas. Primeiramente, foram produzidos modelos na escala1/6, em MDF de $3 \mathrm{~mm}$, fabricados em máquina $\mathrm{CNC}$ laser, permitindo verificar 0 funcionamento dos diversos tipos de encaixe e estabilidade da estrutura. $O$ segundo modelo foi produzido na mesma máquina, em escala 1/50, em compensado pinus, visando avaliar as adaptações qualitativamente, em especial, os efeitos de recuos de fachadas e o emprego das tipologias.

A estratégia de adaptação do pavilhão se dá em dois níveis: tipológico e ambiental. De um lado, a adaptação tipológica considerou tipos arquitetônicos da tradição da arquitetura 
residencial brasileira. De outro, a adaptação ambiental introduziu estratégias de adaptação do edifício aos trópicos. Trata-se de uma tentativa de constituir a Wikihouse brasileira - a WikiHouse.br.

\section{Adaptação Tipológica}

O modelo arquetípico dos projetos piloto das WikiHouses está fundamentado na casa com duas águas e chaminé, com superfícies expostas a diferentes condições climáticas (sol, chuva, vento, neve etc.). Tal modelo têm sido uma solução prototípica recorrente na produção de arquitetura contemporânea, particularmente no trabalho de arquitetos europeus e norte-americanos, a exemplo da Casa em Leymen, Haut-Rhin, projetada por Herzog e De Meuron, em 1996; e a icônica Casa Vanna Venturi, em Chestnut Hill, na Pensilvânia, projetada por Robert Venturi, 1959.

A adaptação deste modelo ao contexto brasileiro, portanto, exige, primordialmente, adequação tipológica. Assim, inicialmente, buscou-se investigar na literatura tipos de habitação predominantes na arquitetura residencial brasileira que, com base em estudos tipológicos realizados por Lemos (1989, p. 14-44) e Colin (2011), podem ser sintetizadas em: (1) casa com telhado de meia-água, (2) casa com telhado de duas águas, (3) casa com telhado de quatro águas, (4) casa com telhado de quatro águas com lanternim, (5) casa com pátio interno, (6) casa tipo pavilhão composto em "L", (7) casa com varanda alpendrada, (8) casa com varanda puxada e (9) coberta com alpendre. Observa-se que a evolução destes tipos, ao longo da história dos assentamentos humanos no Brasil, visou quase sempre a melhor adaptação ao clima tropical, incorporando soluções que permitissem proteção solar, iluminação e ventilação adequadas. (Figura 2).

A partir disto, foram avaliadas possibilidades de adaptação da WikiHouse 3.0 a esses tipos, conforme critérios simples como geometria, economia, desempenho e morfologia. Do ponto de vista da geometria, avaliou-se a facilidade ou dificuldade de adaptação geométrica do modelo ao tipo brasileiro. No que se refere à economia, considerou-se o consumo de maior ou menor número de peças. Em relação ao desempenho, observou-se, dentre os diversos tipos, aqueles que teriam melhor performance nos trópicos. Por fim, com relação à morfologia, estudou-se a capacidade de adequação do tipo à moradia de caráter emergencial. A avaliação não visou converter o modelo Wikihouse no tipo brasileiro, ipsi literis, mas incorporar qualidades do tipo ao modelo, considerandose proximidade com a proposta do grupo WikiHouse.

Em síntese, determinados tipos como casas de quatro águas (com ou sem lanternim), bem como casas com anexação de alpendres demonstraram ser geometricamente mais complexos para serem adaptados, pois se tornam bastante laboriosas para serem executadas por meio do sistema de construção friction-fit connections, ainda que seja tecnicamente possível. Por outro lado, a adaptação tipológica de casas com telhado em duas águas, meia água e casa com pátio demostrou ser mais exequível e mais adequada ao propósito programático (habitação para emergência social e pós-desastre).

\section{Adaptação Ambiental}

As adaptações do sistema WikiHouse ao clima do Nordeste do Brasil foram orientadas pelas lições de Armando de Holanda em seu manual Roteiro para Construir no Nordeste (1976), Holanda elencou um conjunto de nove estratégias que permitem projetar e construir, visando um "melhor desempenho da edificação como instrumento de amenização dos trópicos" (Holanda, 1976, p.15) - "criar uma sombra, recuar as paredes, vazar muros, proteger as janelas, abrir portas, continuar os espaços, construir com pouco, conviver com a natureza e construir frondoso". (HOLANDA, 1976, p.1565).

Primeiramente, buscou-se identificar dentre as estratégias descritas por Holanda (1976) aquelas que mais se aplicavam à adaptação das superfícies exógenas da WikiHouse para que tivessem melhor desempenho nos trópicos. Chegou-se a duas estratégias: recuar as paredes e vazar os muros. (Figuras 2 e 3).
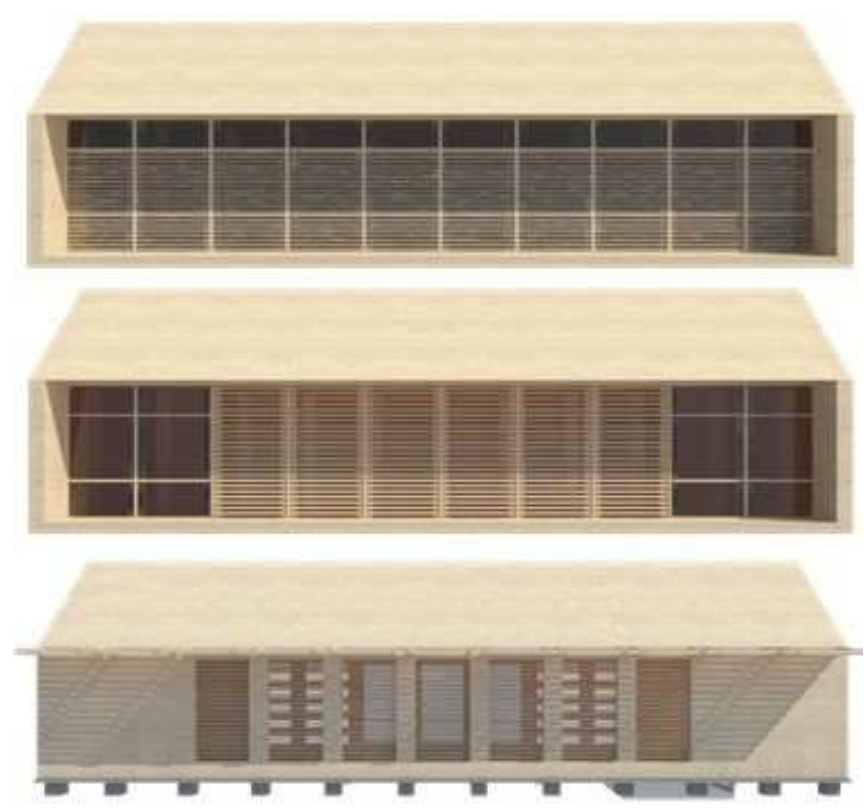

Figura 2: Adaptações exógenas do sistema WikiHouse aos trópicos

Os recuos das paredes geram sombras essenciais para a proteção da edificação contra a forte incidência solar do nordeste brasileiro. De acordo com Holanda (1976, p.21), as "áreas sombreadas e abertas desempenham a função de filtros de coadores de luz, suavizando suas asperezas e fornecendo-a repousante antes de atingir os ambientes internos". Ainda de acordo com Holanda, "as casas de antigos engenhos possuíam esses locais sombreados: varandas corridas em torno do corpo da edificação ao longo da fachada principal" (Holanda, 1976, p.21). Desta forma, buscou-se, desenvolver duas alternativas, uma com recuos nas paredes frontais e outra com recuos das laterais. A opção por uma outra poderá ser determinada pela orientação das edificações, que determinará quais faces receberão mais ou menos incidência solar durante o dia. 


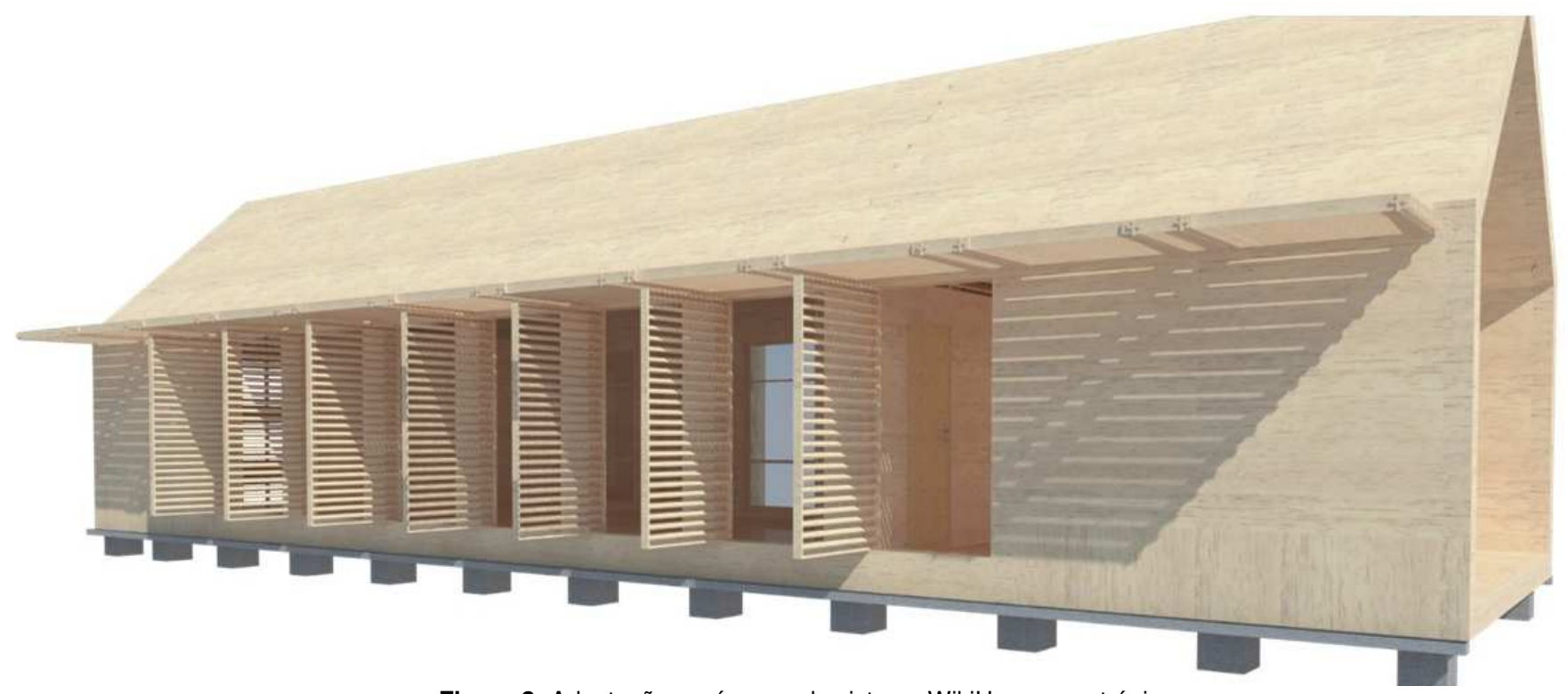

Figura 3: Adaptações exógenas do sistema WikiHouse aos trópicos.

A permeabilidade das empenas é outro aspecto essencial para facilitar o escoamento da ventilação no artefato arquitetônico, além de possuir grande potencial estético. Holanda (1976, p. 25) sugere a "combinação de paredes compactas com panos vazados para que filtrem a luz e deixem a brisa penetrar", tirando "partido das imensas possibilidades construtivas e plásticas do elemento vazado" (Idem). Destaca ainda que, " as primeiras manifestações da arquitetura moderna no Nordeste, com a presença de Luiz Nunes, no Recife, entre os anos de 1934 e 1936, já incorporavam o cobogó numa linguagem plástica tropical, sendo esse elemento, no entanto, praticamente abandonado nos projetos posteriores". (Holanda, 1976, p.21).
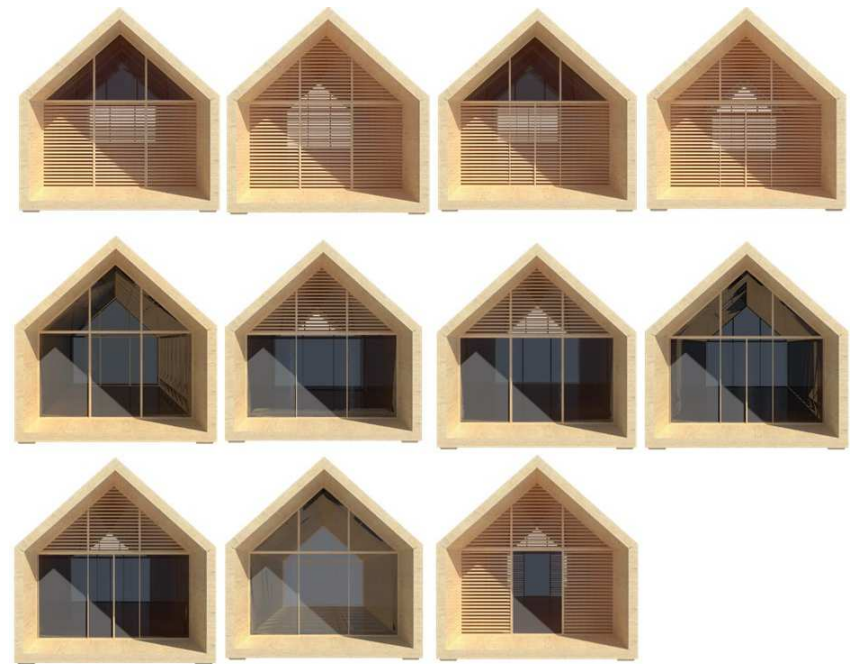

Figura 4: Variações tipológicas dos planos permeáveis

Assim, foram incorporadas ao modelo esquadrias venezianas e micro-telas para a vedação, permitindo a visibilidade do exterior e a convivência dos ambientes com a natureza, bem como o controle solar. Além disso, a inserção de bandeiras nas fachadas, compostas por veneziana e micro-tela, permite a entrada de luz e vento. A permutação desses materiais nas modulações dos planos de esquadria permitiu o desenho de variações, resultando em dezessete tipos. As esquadrias se alternam entre portas pivotantes, de giro e de correr. (Figura 4).

Posteriormente, identificou-se estratégias que tinham maior impacto no desempenho interno da habitação, tais como abrir portas e continuar espaços. A abertura de portas possibilita "a fluência entre a paisagem e a habitação, entre o exterior e o interior, é um convite ao contato entre os mundos coletivo e individual" (Holanda, 1976, p.33). Além disto, as portas permitem a inserção de bandeiras que facilitam a aeração, podendo também serem vazadas com o mesmo objetivo. "As portas rasgadas, guarnecidas com bandeiras abertas de ferro da habitação do século passado, permitiam a tiragem de ar dos ambientes, com o inconveniente de não possibilitar 0 controle da propagação de ruídos entre os cômodos" (Idem). Assim, buscou-se introduzir portas vazadas, com bandeiras em micro-tela, tendo em vista o custo.

A fluidez espacial ou continuidade dos espaços, possibilitada pela inserção de paredes a meia altura, alvenarias vazadas ou diferenças de nível, também atua como instrumento de amenização da arquitetura aos trópicos, "as paredes a meia altura, além de contribuírem para a continuidade do espaço, permitem que o ar circule livremente e atravesse a edificação". (Holanda, 1976, p.33). Desta maneira, buscou-se dotar a habitação de leiautes internos mais amplos, com o mínimo de divisões internas, mas preservando a privacidade dos habitantes. Além disso, as paredes permitem a introdução de elementos vazados em altura - uma estratégia para possibilitar a continuidade, resguardando espaços íntimos. (Figura 5). 


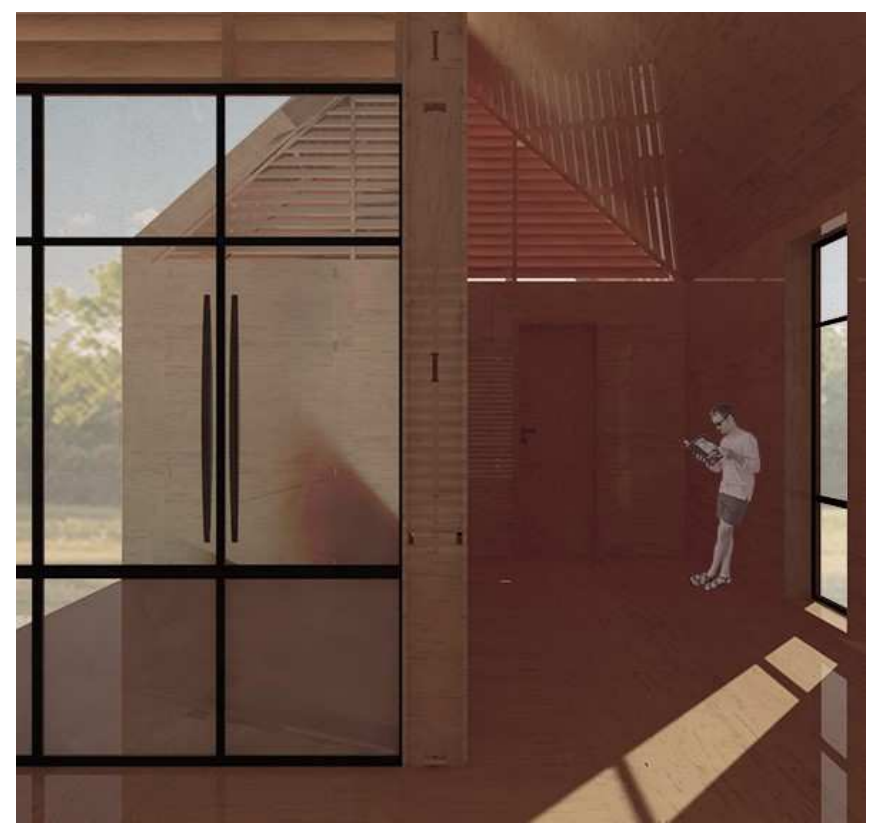

Figura 5: Fluidez espacial e integração entre os ambientes interior e exterior pela permeabilidade das paredes.

Por fim, compreende-se que as demais estratégias sugeridas por Holanda são intrínsecas ao modelo ou ao local em que os artefatos arquitetônicos serão inseridos, bem como a ideia de construir com pouco. Neste aspecto, a adaptação visou à utilização de poucos materiais e à padronização construtiva, mesmo possibilitando variação e personalização. Emprega-se a madeira, como elemento primordial por possuir bom desempenho térmico, não sendo necessária a utilização de revestimentos externos, nem o isolamento térmico, aplicandose apenas a resina acrílica para proteção do material.

\section{Limitações de adaptação}

As tentativas de adaptação demonstraram evidentes limitações, em parte, concernentes ao próprio método frictionfit connection e, em parte, relativas à rigidez do modelo Wikihouse 3.0. Tais dificuldades se referem principalmente à dimensão e à introdução de componentes vazados, elementos de proteção das fachadas e sistemas de escoamentos de água.

Dimensão - Por ser um sistema constituído por peças fabricadas em CNC a partir de cortes de placas de madeira compensada, o tamanho das peças está condicionado às dimensões máximas das placas, dificultando o projeto de espaços mais amplos, mais generosos, pois a estrutura composta pelas peças não permite vãos largos, tendo como resultado esquemas quase sempre pavilhonares.

Componentes vazados - Os elementos vazados, bem como as venezianas, pela própria natureza geométrica, demandam maior número de peças e encaixes para incorporação à arquitetura, tornando-se um limitador, ainda que seja tecnicamente possível. Observou-se que, muitas vezes, os encaixes desses elementos conflitam com os encaixes da estrutura da habitação, resultando em prejuízos de ordem prática e estéticas. Ủma opção é a incorporação de elementos ou esquadrias pré-fabricadas, independentes do sistema construtivo da moradia, o que poderia encarecer a proposta.

Proteção de fachadas - A anexação de alpendres e beirais, do mesmo modo, apresenta conflitos de encaixes e, principalmente, instabilidade das peças se propostos beirais extensos em balanço, limitando os mesmos a curtas dimensões. Evidentemente, a criação de apoios para esses elementos, mais característicos dos alpendres das antigas casas de engenho, podem ser objeto de proposição, no entanto, procurou-se respeitar na medida do possível, as características do modelo proposto pela WikiHouse 3.0, sugerindo adequações que não descaracterizassem em demasia esse modelo.

Limitação no escoamento de água - A introdução de calhas para escoamento e reaproveitamento das águas da chuva, especialmente em contextos ambientais com altas precipitações exigem dimensões mais generosas, mas que podem, no entanto, fragilizar os montantes da estrutura pela possibilidade de cortes, caso as calhas sejam embutidas. Nestes casos, o modelo fica limitado à introdução de telhas.

Certamente, esses aspectos são tecnicamente superáveis, mas atuam como obstáculos à adaptação, principalmente quando se pensa em um artefato residencial de baixo custo para os propósitos investigados neste trabalho. Compreendese, pelos aspectos elencados que, apesar da altivez do propósito da WikiHouse, a adaptação não é tão simples como se propaga.

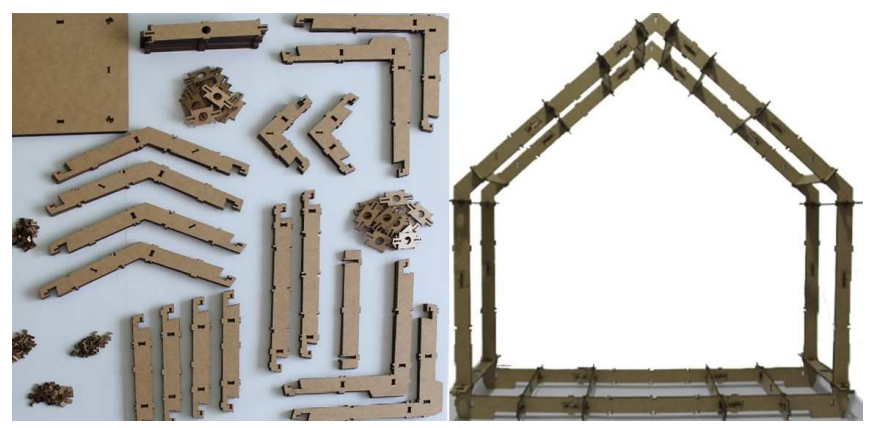

Figura 6: Modelos físicos, fabricados digitalmente.

\section{WikiHouses para Emergências Sociais e Urbanismo Pós-traumático nos Trópicos}

\section{Situações emergenciais ou urbanismo pós- traumático}

O termo "urbanismo pós-traumático" (Lahoud, 2010) se refere a situações de emergência social em que determinada população urbana passa por um trauma decorrente de desastres naturais ou conflitos civis, acarretando a perda de suas habitações, mas onde se verifica a resiliência. Segundo Adrian Lahoud (2010, p.14-23), "o trauma é uma ocorrência que excede a sistematização, é uma exceção e coleção de singularidades. É um momento pouco divulgado e sem precedentes, chega sem aviso, sendo um evento inassimilável que nos deixa perdidos em um mar de sensações excessivas. No momento do trauma, o indivíduo se torna um exilado de 
sua própria paisagem psíquica, sendo um intruso estrangeiro em uma terra desconhecida. É um drama em que tanto o passado e o futuro estão em jogo, chegando ao ponto em que o sistema deve se reinventar ou perecer. O local que sofreu 0 trauma busca a resiliência - a capacidade de um sistema de se recuperar depois de absorvido algum choque, porém a recuperação nunca é um fácil retorno ao seu estado anterior. Após a absorção do choque deve-se explorar e ensaiar novas formas de se estabilizar".

Os desastres naturais e os conflitos que ocorrem em todo o mundo, destroem cidades e deixam pessoas desamparadas, refugiadas e em situações de emergência, surgindo a necessidade de reabrigá-las. Para que isso aconteça, o abrigo está para além da oferta de um teto, é um meio de garantir saúde, segurança, privacidade e dignidade aos moradores. Para Kasper Guldager (2013, p.05), os abrigos devem ser fornecidos de forma apropriada em um curto prazo e ser de fácil montagem e desmontagem, já que muitas vezes esses abrigos são apenas temporários.

Observando a dinâmica de locais que experimentaram traumas urbanos, constata-se duas circunstâncias típicas:

(1) aquelas nas quais ocorre devastação parcial ou leves danos à comunidade, demandando abrigos temporários para curto período. Por exemplo, fortes chuvas e transbordamento de rios, que alagam cidades ou comunidades, porém não destroem suas casas, apenas as deixam inacessíveis por um determinado período de tempo, cerca de semanas ou meses.

(2) aquelas em que ocorre a devastação total, danos mais permanentes na estrutura urbana, de maneira que seja imperiosa a reconstrução da área totalmente. Em geral, são situações decorrentes de passagens de furacões, bombardeios em guerras civis, tsunamis, incêndios de grandes proporções, terremotos, colapsos de infraestruturas como barragens e outros. Nestes casos, é necessário que se abrigue indivíduos de forma mais confortável por um período maior de tempo, pois a reconstrução da comunidade ou da cidade pode ser bastante lenta, chegando a demorar anos ou décadas.

Assim sendo, procurou-se desenvolver dois protótipos que se adequassem a situações de curta e longa permanência, tendo como referência o modelo hipotético empregado, previamente, no desenvolvimento de ensaios de adaptação tipológica e ambiental.

\section{Devastação Parcial - curta permanência}

Para as situações de devastação parcial, foi proposto um pavilhão genérico, que, por não possuir divisões internas, pode se adaptar a qualquer uso que a comunidade necessitar após o trauma. Esse pavilhão pode ser adaptado para refeitórios, banheiros ou outros usos coletivos que a comunidade necessitar para se reestabelecer rapidamente.

\section{Devastação Total - longa permanência}

Para as situações nas quais os indivíduos passam por ocorrências de perda total de suas moradias, ficando em condições sub-humanas por um período de tempo maior que a situação anterior, é necessária, na maior parte das vezes, a reconstrução da comunidade ou constituição de novas vilas ou cidades de forma rápida para acomodá-los. Assim, foi proposta variações do pavilhão genérico, por meio do acréscimo de divisões internas. Essas unidades são facilmente adaptáveis, personalizáveis, podendo ter seu leiaute interno reconfigurado para atender as necessidades de cada família e, com isto, prover maior conforto e privacidade, geralmente ausentes em alojamentos comunitários. (Figura 7)

Além disso, foram pensados arranjos de vizinhança para melhor organizar a reconstrução das áreas atingidas. (Figura 8).
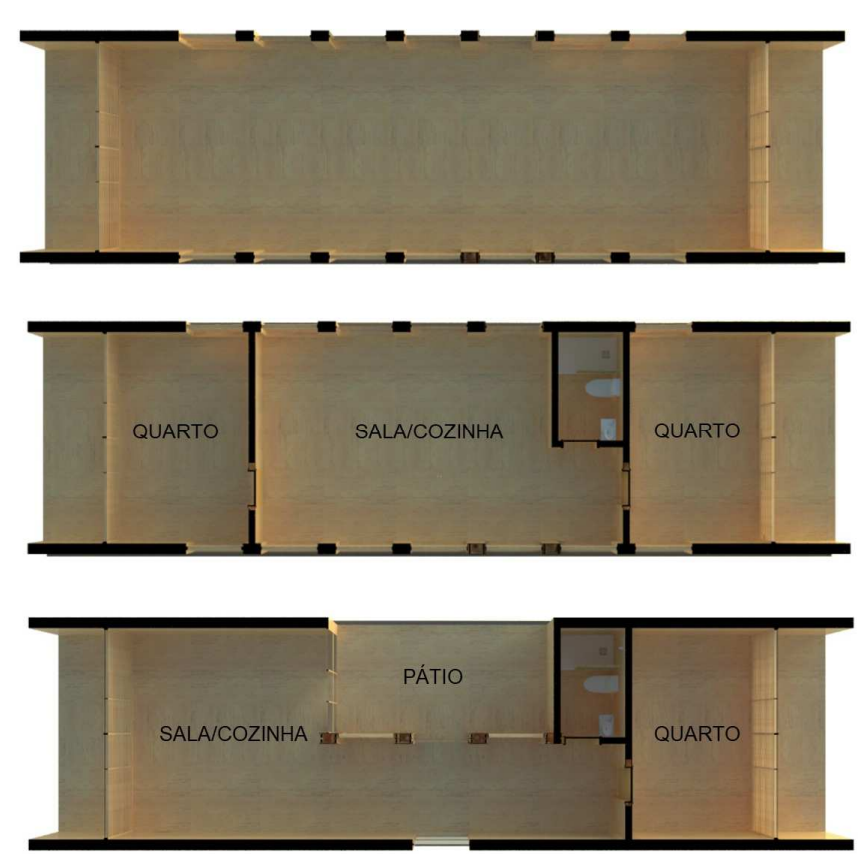

Figura 7: Arranjos internos para situação para moradias de curta e longa permanência. Arranjo 1: Pavilhão genérico. Arranjo 2: é composta por 2 quartos, sala, cozinha e BWC. Arranjo 3: 1 quarto, sala, cozinha, BWC e um pátio (modelo pátio).

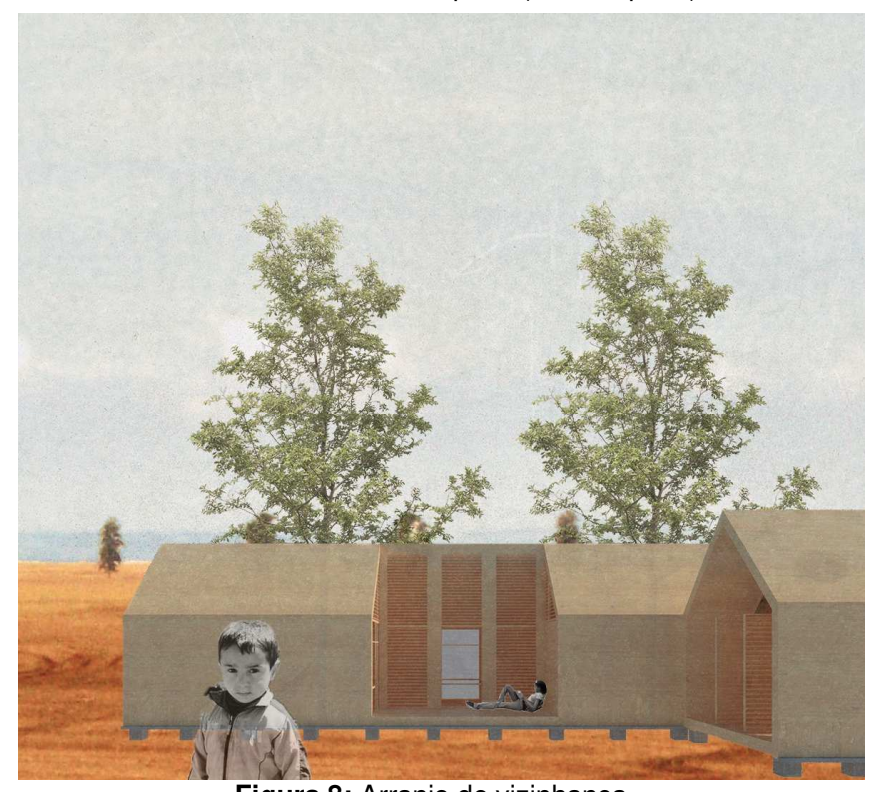

Figura 8: Arranjo de vizinhança. 


\section{Montagem e Desmontagem}

A montagem e desmontagem da casa é realizada através de 05 passos. (Figura 09).

Passo 01: A casa deve ficar solta do solo evitando a umidade direta em sua estrutura. O solo deve ser batido para receber uma base de apoio, podendo ser blocos de concreto préfabricados ou estruturas metálicas de apoio. Se o local estiver inclinado, a base pode ser projetada de forma que a superfície de apoio dos pórticos esteja alinhada no mesmo plano.

Passo 02: A infraestrutura básica da casa (cisternas, tubulações hidráulicas, instalações elétricas e outras que forem necessárias) deve ser distribuída pela parte inferior da mesma, inclusive, facilitando possíveis manutenções por ela ser erguida do chão.

Passo 03: Por se tratar de uma estrutura de encaixes e ter a característica de pórticos, deve-se primeiramente unir as peças formando os pórticos na posição horizontal, sobre o piso, para somente depois de montados serem erguidos um a um para posterior travamento/conexão das peças transversais.

Passo 04: Após todo o esqueleto erguido, deve-se conectar as placas de travamento/vedação. Essas servem para fechar as paredes e deixar a estrutura firme e rígida. Antes de colocar todas as peças externas deve-se passar todas as as instalações elétricas e hidráulicas.

Passo 05: Inserção das Esquadrias e resina para proteção das peças e vedação das fissuras.

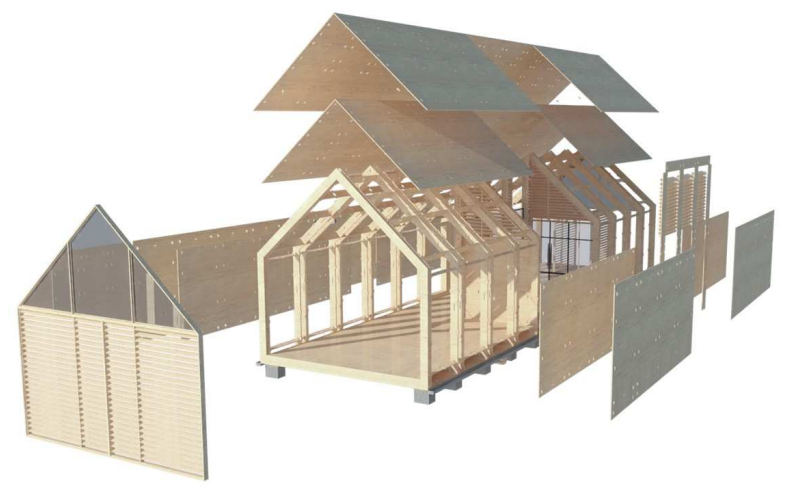

Figura 9: Vista explodida.

\section{Conclusão}

O trabalho investigou casas fabricadas digitalmente para a produção de habitação de caráter emergencial no contexto brasileiro, baseando-se em sistemas Open Source Construction, em particular as Wikihouses. Todavia, tais sistemas necessitam de adaptação ao contexto ambiental local, que podem ser orientadas pelas estratégias de Armando de Holanda (HOLANDA, 1976). Foram feitas tentativas, que permitiram identificar dificuldades de desenvolver determinadas adaptações, por exemplo, a inserção de cobogós, beirais, calhas e cobertas. Dessa maneira, nota-se que esses sistemas possuem limitações, pois dependem de um tamanho máximo das peças, dificultando a adequação ao contexto local. Foram verificadas dificuldades de introdução de componentes vazados; introdução de proteção de fachadas como e de alpendres e beirais mais largos; introdução de calhas para escoamento pela fragilidade das peças. Embora esses aspectos sejam superáveis, como a especulação nos mostra, limitam o emprego do modelo como uma arquitetura residencial de baixo custo para os propósitos investigados neste trabalho.

Não obstante, o trabalho pode ser levado a um estudo mais aprofundado com a inversão da metodologia, criando peças e partes da habitação diretamente a partir de tipos predominantes de arquitetura residencial no Brasil, em detrimento da adaptação do modelo WikiHouse.

\section{Referências}

Celani, G.. (2010, Jan). Os Workshops do SIGraDi 09 e a fabricação digital no Brasil. Retrieved from http://www.vitruvius.com.br/revistas/read/drops/10.030/2114.

Celani, G.. (2013). Lapac 2006-2013 laboratório de automação e prototipagem para arquitetura e construção. Campinas, SP: Biblioteca Central Cesar Lattes.

Cobbers, Arnt \& Jahn, Oliver. (2014). Prefab Houses. Taschen.

COLIN, Silvio. (2011). Tipos e padrões da arquitetura civil colonial. Retrieved from: https://coisasdaarquitetura.wordpress.com/2011/02/28/tipos-epadroes-da-arquitetura-civil-colonial-i/.

Dunn, Nick. (2012) Digital fabrication in architecture. Laurence King.

Guldager, Kasper. Research, 2013

Holanda, Armando de. (1976). Roteiro para construir no Nordeste. Recife: MDU/UFPE.

Kolarevic, Branko (Ed.). (2004). Architecture in the digital age: design and manufacturing. Taylor \& Francis.

Khoshnevis, B. (2004). Automated construction by contour crafting related robotics and information technologies. Automation in construction. v.13, n.2, p. 05-19.

Lahoud, Adrian. (2010, Set/Out). Post-traumatic Urbanism. Architectural Design. p. 14-23.

Lemos, Carlos Alberto Cerqueira. (1989). História da casa brasileira. Editora Contexto.

Mit news. (2008) The House That Larry Built. Retrieved from Http://News.Mit.Edu/2008/Arch-Sass-0703.

Passaro, Andrés, \& Rohde, Clarice. (2015). "Casa Revista: arquitetura de fonte aberta." Blucher Design Proceedings 2.3.

Passaro, Andrés, \& Rohde, Clarice. (2014). Casa Revista. Anais

Sass, Lawrence e Botha, Marcel. (2006). The Instant House: A Digital Fabrication System for Design Model and Full Scale Wood Frame Housing, IS\&T Digital Fabrication Conference, Denver, Colorado.

Smith, Ryan E. (2011). Prefab architecture: A guide to modular design and construction. John Wiley \& Sons.

Votava, Kate. (2006). Envolve House. Flexible dwelling for postmodern costumer culture. Master thesis. University of Cincinnati. School of Architecture and Interior Design. p.32.

Wikihouse. (2016). Retrieved from: Http:/Www.Wikihouse.Cc 